\title{
Electrodeposition and Characterization of W-rich NiW Alloys from Citrate Electrolyte
}

\author{
Mohamed Benaicha ${ }^{1, *}$, Mahdi Allam ${ }^{2}$, Achour Dakhouche ${ }^{2}$, Meriem Hamla $^{1}$ \\ ${ }^{1}$ Energetic and Solid-State Electrochemistry Laboratory, Dept. of Processes Engineering, Faculty of \\ Technology, Ferhat Abbas-Setif1 University, Setif, 19000, Algeria. \\ ${ }^{2}$ Department of chemistry, Faculty of Sciences, Mohamed Boudiaf University, M'sila, 28000, Algeria. \\ *E-mail: mdbenaicha@yahoo.fr
}

doi: $10.20964 / 2016.09 .17$

Received: 21 May 2016/ Accepted: 11 July 2016 / Published: 7 August 2016

\begin{abstract}
The electrodeposition of NiW alloys from citrate electrolyte was studied in an effort to evaluate the effect of applied potential and solution $\mathrm{pH}$ on the composition limit and the properties of the deposits. Electrochemical measurements employing cyclic voltammetry $(\mathrm{CV})$, potentiodynamic polarization and electrochemical impedance spectroscopy (EIS) were used to investigate the codeposition process, corrosion resistance and HER electrocatalytic properties of the deposits. The deposits morphology was characterized by scanning electron microscopy (SEM) and the surface composition of coatings was ascertained by Energy dispersive $\mathrm{x}$-ray analysis (EDXA). Possibility of W-rich NiW alloys electrodeposition from ammonia-free citrate electrolyte at room temperature was confirmed. The tungsten content was close to 32 at.\% in deposits obtained from a quasi-neutral solution. Structural study revealed that all of $\mathrm{NiW}$ coated alloys were amorphous regardless of $\mathrm{W}$ content. On the other hand, it was found that Ni-W alloys deposited at -1.4 V/CSE (having about 14 at.\% W) are good electrode materials as cathode for HER following the Volmer-Heyrovsky mechanism with substantial surface-adsorbed hydrogen while alloys plated at $-1.2 \mathrm{~V} / \mathrm{SCE}$ (having about $32 \mathrm{wt} . \% \mathrm{~W}$ ) were of excellent corrosion resistance in $3.5 \% \mathrm{NaCl}$ solution.
\end{abstract}

Keywords:Nickel-tungsten alloys; Electrodeposition; Hydrogen evolution reaction; Electrocatalysis; Corrosion.

\section{FULL TEXT}

(C) 2016 The Authors. Published by ESG (www.electrochemsci.org). This article is an open access article distributed under the terms and conditions of the Creative Commons Attribution license (http://creativecommons.org/licenses/by/4.0/). 